\title{
Measurement of the Contact Potential Difference between a Powder Bed and a Metal $\dagger$
}

\author{
Hideto Yoshida and Toshihiko Fukuzono \\ Dept. of Chem. Eng., Hiroshima Univ.,* \\ Hiroaki Masuda \\ Dept. of Chem. Eng., Kyoto Univ.,**
}

\begin{abstract}
Experimental and theoretical studies have been conducted on the measurement of the contact potential difference between a powder bed and a metal. A new model was proposed for the analysis of the experimental data. The model analysis indicated that accurate contact potential differences are obtained only when the electric charge of the powder bed is assumed to be zero. It was found that the absolute value of the contact potential difference decreased with an increase in relative humidity. The contact potential changed with the particle surface-modification by methanol vapor. However the original contact potential difference was obtained again when the methanol evaporated completely from the particle surface.
\end{abstract}

\section{Introduction}

In the powder and granular material processing, inconveniences such as dust adhesion and production interference frequently occur due to the electrically-charged powder resulting from contact between particles and equipment wall surface during mixing, pulverizing, classification, and other dry powder handlings. However, detailed investigation has not been reported regarding accurate measuring methods and measured values of the contact potential difference between particles and a metal, which constitutes the basis of the charging mechanism. In the process of surface modification of powders, which has recently been attracting the attention of engineers and the industry, reliable values of contact potential difference ${ }^{4}$ between a powder and a metal become essential for the estimation of the charge signs and the amount of the charge of the particles.

Penny et $a .^{3)}$ measured the contact potential

* Higashi-Hiroshima, Kagamiyama, 724 JAPAN

TEL. 0824-22 7111

** Yoshida-Honmachi, Sakyoku, 606 JAPAN TEL. 075-753-5565

$\dagger \quad$ This report was originally printed in $J$. Soc. Powder Technol. ogy, Japan, 28, 226-231 (1991) in Japanese, before being translated into English with the permission of the editorial committee of the Soc. Powder Technology, Japan. difference between a powder bed and a metal, but their experimental values contain problems since the time dependence of the measured values was not taken into account and no temperature and humidity control were carried out for the powder bed.

In this paper, an experimental apparatus measuring contact potential differences between powders and a metal was built as a device which provides reliable measured values. A new model was proposed to interpret the measurement results, and interesting findings have been obtained.

\section{Experimental Apparatus}

Figure 1 shows the experimental apparatus used for this investigation. The measuring apparatus is based on the Kelvin method. ${ }^{1)}$

The measuring apparatus consists of an upper vibrating electrode (3), a 3-mm-depth powder bed (5), a lower electrode (4), an external variable d.c. power supply (6), and an electrometer for electric current measurement (Advantest, TR8652) (1). The upper and lower electrode surfaces are gold-plated to eliminate the effects of the adhering impurities on the measurement errors.

The upper electrode has a diameter of $20 \mathrm{~mm}$ and the lower electrode a diameter of $30 \mathrm{~mm}$, while the vibration frequency and amplitude of 

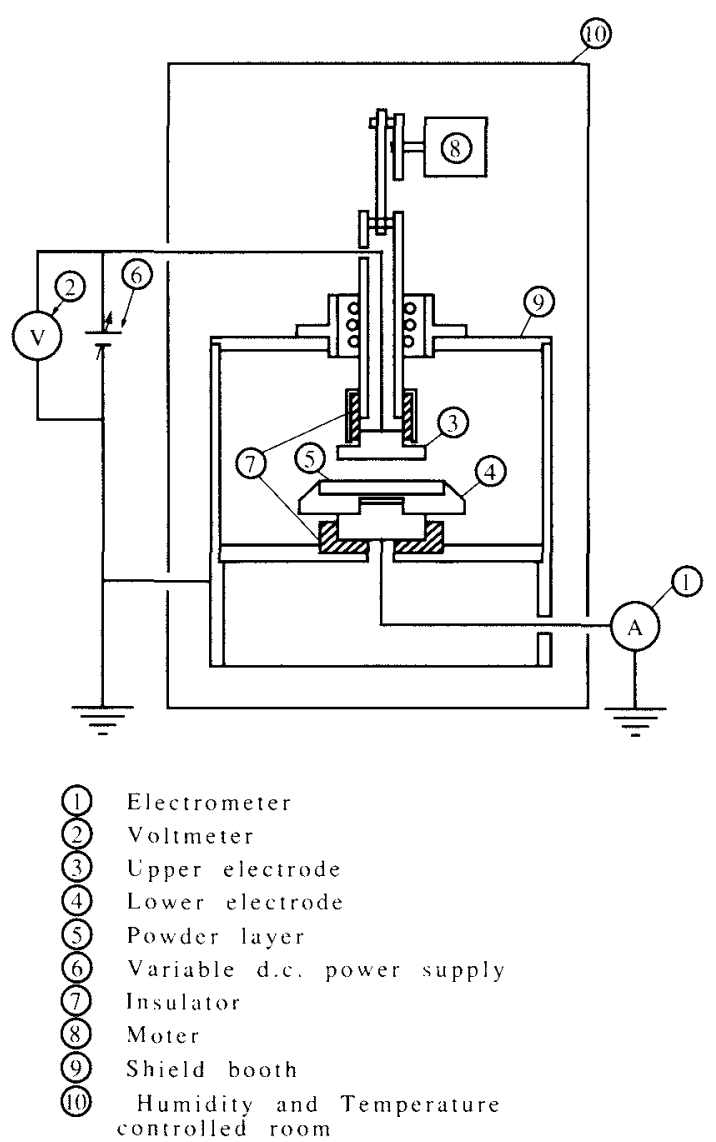

Fig. 1 Experimental apparatus

the upper electrode are $120 \mathrm{rpm}$ and $5 \mathrm{~mm}$, respectively. An $\mathrm{SiC}$ powder (mass median diameter, $0.62 \mu \mathrm{m}$ ) is selected, compressionformed to a specified packing ratio, and subjected to the experiment.

Figure 2 shows the electric circuit of the measuring apparatus. The contact potential difference between the metal and the powder generates electric charges in the lower portion of the powder bed and at the lower electrode surface which induce charges at the upper electrode surface due to the influence of the lines of electric force from this charge. Varying the upper electrode periodically varies the charges on the upper electrode surface with time and allows the flow of current through the circuit.

Applying a voltage to the upper electrode, which does not generate current in the circuit even if the electrode is vibrated, equalizes the potential with that caused by the contact potential difference. Therefore, the magnitude of the current variation depends on the intensity of the d.c. current applied to the upper electrode, and the applied voltage at which the magnitude of the current becomes zero corresponds to the contact potential difference.

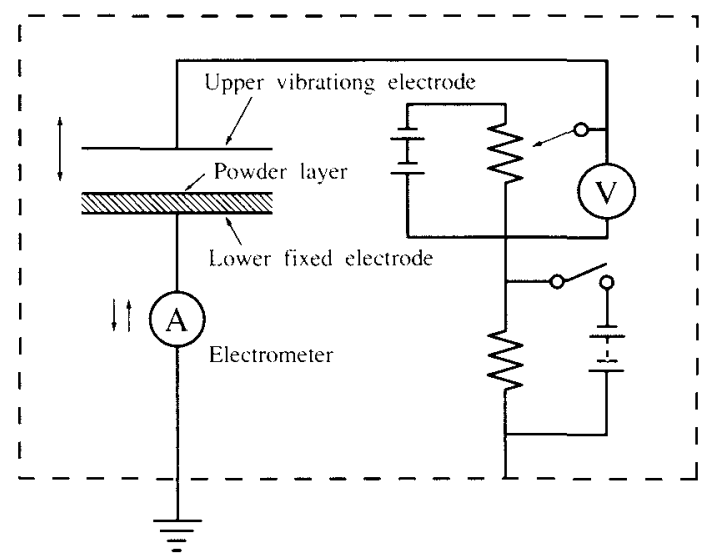

Fig. 2 Electric circuit of measuring system

\section{Measuring Model}

An investigation has been carried out to some extent on the surface potential using the Kelvin method, but the physical meaning of the measured values has not been interpreted accurately. In this paper, a new model shown below is used in a mathematical investigation.

Figure 3 shows a measuring system consisting of an upper electrode, a powder bed, and a lower electrode. Between the powder bed and the lower electrode, positive and negative charges are induced by the contact potential difference. Between the bottom of powder bed and the lower electrode, an extremely small clearance (about $4 \AA^{2)}$ ) is assumed. Then, letting the surface charge density of the powder bed bottom and upper electrode be $\rho_{\mathrm{s}}$ and $\rho_{\mathrm{se}}$, respectively, the upper electrode moves in accordance with the following equation.

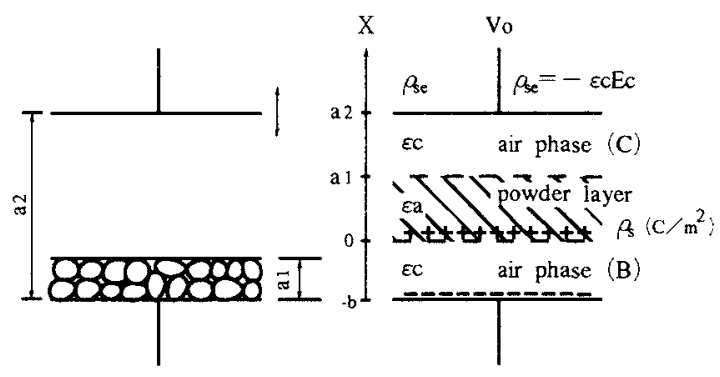

Fig. 3 Model of measuring system 
$a_{2}(t)=\alpha_{1}+\alpha_{2} \cos (\omega t)$

where, $\alpha_{1}$ is a mean electrode spacing and $\alpha_{2}$ the amplitude. Since there is no space charge in the air phase $(C),(B)$, the potential is given by the following equations.

$$
\begin{aligned}
& \mathrm{V}_{\mathrm{c}}=\mathrm{K}_{\mathrm{cl} 1 \mathrm{x}}+\mathrm{K}_{\mathrm{c} 2} \\
& \mathrm{~V}_{\mathrm{b}}=\mathrm{K}_{\mathrm{b} 1} \mathrm{x}+\mathrm{K}_{\mathrm{b} 2}
\end{aligned}
$$

The constants $\mathrm{K}_{\mathrm{c} 1}, \mathrm{~K}_{\mathrm{c} 2}, \mathrm{~K}_{\mathrm{b} 1}, \mathrm{~K}_{\mathrm{b} 2}$ are determined by the potential boundary conditions.

The potential in the powder bed is given by the following equation.

$$
\mathrm{V}_{\mathrm{a}}=-\frac{\rho_{\mathrm{B}} \mathrm{X}^{2}}{2 \varepsilon_{\mathrm{a}}}+\mathrm{K}_{\mathrm{a} 1 \mathrm{X}}+\mathrm{K}_{\mathrm{a} 2}
$$

where, $\rho_{\mathrm{B}}$ and $\varepsilon_{\mathrm{a}}$ are the volume charge density and the permittivity, respectively. Now, applying the Gaussian divergence theorem to the powder bed and powder bed bottom, we get

$$
\left.\begin{array}{l}
\varepsilon_{\mathrm{c}} \mathrm{E}_{\mathrm{c}} \mathrm{S}-\left.\varepsilon_{\mathrm{a}} \mathrm{E}_{\mathrm{a}}\right|_{\chi=0} \mathrm{~S}=\rho_{\mathrm{B}} \mathrm{a}_{1} \mathrm{~S} \\
\varepsilon_{\mathrm{c}}\left(-\mathrm{K}_{\mathrm{c} 1}\right)-\varepsilon_{\mathrm{a}}\left(-\mathrm{K}_{\mathrm{a} 1}\right)=\rho_{\mathrm{B}} \mathrm{a}_{1} \mathrm{~S}
\end{array}\right\}
$$

where, $\mathrm{S}$ is the surface area of the electrode, $\rho_{\mathrm{s}}$ the surface charge density of the powder bed, and $\mathrm{E}$ the intensity of the electric field.

Since the potential is equal at the interface of each region, we get the boundary conditions for the following potentials.

$$
\begin{aligned}
& \left.\mathrm{V}_{\mathrm{c}}\right|_{x=\mathrm{a} 2}=\mathrm{V}_{0} \\
& \left.\mathrm{~V}_{\mathrm{a}}\right|_{x=0}=\left.\mathrm{V}_{\mathrm{b}}\right|_{x=0} \\
& \left.\mathrm{~V}_{\mathrm{c}}\right|_{x=\mathrm{a} 1}=\left.\mathrm{V}_{\mathrm{a}}\right|_{x=\mathrm{a} 1} \\
& \left.\mathrm{~V}_{\mathrm{b}}\right|_{x=\mathrm{b}}=0
\end{aligned}
$$

Because we have six equations (5), (6), (7-1)-(74) and six unknown variables $K_{a 1}, K_{a 2}, K_{b 1}, K_{b 2}$, $\mathrm{K}_{\mathrm{c1}}, \mathrm{K}_{\mathrm{c} 2}$, we can determine the constants analytically as follows:

$$
\begin{aligned}
\mathrm{K}_{\mathrm{a} 1} & =\frac{\left[-\frac{\rho_{\mathrm{B} \mathrm{a}_{1}^{2}}}{2 \varepsilon_{\mathrm{c}}}+\frac{\rho_{\mathrm{a}} \mathrm{b}}{\varepsilon_{\mathrm{c}}}+\frac{\rho_{\mathrm{B}} \mathrm{a}_{1}^{2}}{\varepsilon_{\mathrm{c}}}-\mathrm{V}_{0}-\frac{\rho_{\mathrm{B}} \mathrm{a}_{1} \mathrm{a}_{2}}{\varepsilon_{\mathrm{c}}}\right]}{\left[\frac{\varepsilon_{\mathrm{a}} \mathrm{a}_{1}}{\varepsilon_{\mathrm{c}}}-\frac{\varepsilon_{\mathrm{a}} \mathrm{a}_{2}}{\varepsilon_{\mathrm{c}}}-\mathrm{a}_{1}-\frac{\varepsilon_{\mathrm{a}} \mathrm{b}}{\varepsilon_{\mathrm{c}}}\right]} \\
\mathrm{K}_{\mathrm{b} 1} & =\frac{\varepsilon_{\mathrm{a}}\left[-\frac{\rho_{\mathrm{B}} \mathrm{a}_{1}^{2}}{2 \varepsilon_{\mathrm{a}}}+\frac{\rho_{\mathrm{s}} \mathrm{b}}{\varepsilon_{\mathrm{c}}}+\frac{\rho_{\mathrm{B}} \mathrm{a}_{1}^{2}}{\varepsilon_{\mathrm{c}}}-\mathrm{V}_{0}-\frac{\rho_{\mathrm{B}} \mathrm{a}_{1} \mathrm{a}_{2}}{\varepsilon_{\mathrm{c}}}\right]}{\varepsilon_{\mathrm{c}}\left[\frac{\varepsilon_{\mathrm{a}} \mathrm{a}_{1}}{\varepsilon_{\mathrm{c}}}-\frac{\varepsilon_{\mathrm{a}} \mathrm{a}_{2}}{\varepsilon_{\mathrm{c}}}-\mathrm{a}_{1}-\frac{\varepsilon_{\mathrm{a}} \mathrm{b}}{\varepsilon_{\mathrm{c}}}\right]}+\frac{\rho_{\mathrm{B}}}{\varepsilon_{\mathrm{c}}}
\end{aligned}
$$

$$
\begin{aligned}
\mathrm{K}_{\mathrm{cl}}= & \frac{\varepsilon_{\mathrm{a}}\left[-\frac{\rho_{\mathrm{B}} \mathrm{a}_{1}^{2}}{2 \varepsilon_{\mathrm{a}}}+\frac{\rho_{\mathrm{s}} \mathrm{b}}{\varepsilon_{\mathrm{c}}}+\frac{\rho_{\mathrm{B}} \mathrm{a}_{1}^{2}}{\varepsilon_{\mathrm{c}}}-\mathrm{V}_{0}-\frac{\rho_{\mathrm{B}} \mathrm{a}_{1} \mathrm{a}_{2}}{\varepsilon_{\mathrm{c}}}\right]}{\varepsilon_{\mathrm{c}}\left[\frac{\varepsilon_{\mathrm{a}} \mathrm{a}_{1}}{\varepsilon_{\mathrm{c}}}-\frac{\varepsilon_{\mathrm{a}} \mathrm{a}_{2}}{\varepsilon_{\mathrm{c}}}-\mathrm{a}_{1}-\frac{\varepsilon_{\mathrm{a}} \mathrm{b}}{\varepsilon_{\mathrm{c}}}\right]} \\
& -\frac{\rho_{\mathrm{B}} \mathrm{a}_{1}}{\varepsilon_{\mathrm{c}}}
\end{aligned}
$$

Then, the charges induced in the upper vibrating electrode can be calculated using the following equation:

$\rho_{\mathrm{se}}=-\varepsilon_{\mathrm{c}} \mathrm{E}_{\mathrm{c}^{\prime}} \rho_{\mathrm{se}}=\varepsilon_{\mathrm{c}} \mathrm{K}_{\mathrm{c} 1}$

In the above equation, $\rho_{\text {se }}$ is the surface charge density on the upper electrode. From Eqs. (10), (11), the electric current can be calculated by Eq. (12).

$$
\mathrm{i}=\mathrm{S}\left[\frac{\mathrm{d} \rho_{\mathrm{se}}}{\mathrm{dt}}\right]=\frac{\mathrm{S} \varepsilon_{\mathrm{a}}^{2} \alpha_{2} \omega \sin (\omega \mathrm{t})\left[\mathrm{V}_{0}-\frac{\rho_{\mathrm{B}} \mathrm{a}_{1}^{2}}{2 \varepsilon_{\mathrm{a}}}-\frac{\rho_{\mathrm{B}} \mathrm{ba}_{1}}{\varepsilon_{\mathrm{c}}}-\frac{\rho_{\mathrm{s}} \mathrm{b}}{\varepsilon_{\mathrm{c}}}\right]}{\left[\frac{\varepsilon_{\mathrm{a}} \mathrm{a}_{1}}{\varepsilon_{\mathrm{c}}}-\frac{\varepsilon_{\mathrm{a}} \mathrm{a}_{2}}{\varepsilon_{\mathrm{c}}}-\mathrm{a}_{1}-\frac{\varepsilon_{\mathrm{a}} \mathrm{b}}{\varepsilon_{\mathrm{c}}}\right]^{2}}
$$

From Eq. (12), the current fluctuates periodi. cally and adjusting the applied voltage to satisfy the following equation at all times brings down the current value to zero.

$$
V_{0}=\frac{\rho_{\mathrm{B}} \mathrm{a}_{1}^{2}}{2 \varepsilon_{\mathrm{a}}}+\frac{\rho_{\mathrm{B}} \mathrm{a}_{1} \mathrm{~b}}{\varepsilon_{\mathrm{C}}}+\frac{\rho_{\mathrm{s}} \mathrm{b}}{\varepsilon_{\mathrm{c}}}
$$

Next, the contact potential difference $\Delta \tilde{V}$ corresponds to the potential difference between the lower electrode and the bottom of the powder bed can be calculated using the following equation together with Eq. (9).

$$
\Delta \widetilde{V}=\int_{-b}^{0} K_{b 1} d x=\frac{\rho_{\mathrm{s}} \mathrm{b}}{\varepsilon_{\mathrm{c}}}+\frac{\mathrm{b} \rho_{\mathrm{B}} \mathrm{a}_{1}}{\varepsilon_{\mathrm{c}}}
$$

A comparison between Eq. (13) and Eq. (14) leads to the relationship between the externally applied voltage $V_{0}$ and the contact potential difference $\Delta \tilde{V}$, which is given by the following equation.

$\mathrm{V}_{0}=\Delta \widetilde{\mathrm{V}}+\frac{\rho_{\mathrm{B}} \mathrm{a}_{1}^{2}}{2 \varepsilon_{\mathrm{a}}}$

From the above equation, the externally applied voltage $V_{0}$ becomes equal to the contact potential difference $\Delta \tilde{V}$ when there is no charge in the powder bed (that is $\rho_{\mathrm{B}} \rightarrow 0$ ). Now apply. ing the generally employed condenser model to the air phase (B) of Figure 3, we have 


$$
\mathrm{C}=\varepsilon_{\mathrm{c}} \frac{\mathrm{S}}{\mathrm{b}}, \quad \mathrm{q}=\mathrm{C} \cdot \Delta \mathrm{V}=\varepsilon_{\mathrm{c}} \Delta \mathrm{V} \frac{\mathrm{S}}{\mathrm{b}}
$$

Hence, the potential difference $\Delta V$ is given by

$$
\Delta \mathrm{V}=\frac{\mathrm{qb}}{\varepsilon_{\mathrm{c}} \mathrm{S}}=\frac{\mathrm{b} \rho_{\mathrm{S}}}{\varepsilon_{\mathrm{c}}}
$$

If there is no charge in the powder bed $\left(\rho_{\mathrm{B}}=0\right)$, the potential difference $\Delta \tilde{V}$ obtained by Eq. (14) would be equal to the potential difference $\Delta \mathrm{V}$ of Eq. (17).

Next, an investigation of the potential of the powder bed top portion is carried out. Substituting Eq. (13) into Eqs. (8) and (9) gives the constants $\mathrm{K}_{\mathrm{a} 1}$ and $\mathrm{K}_{\mathrm{b} 1}$ as follows:

$\mathrm{K}_{\mathrm{a} 1}=\frac{\rho_{\mathrm{B}} \mathrm{a}_{1}}{\varepsilon_{\mathrm{a}}}, \quad \mathrm{K}_{\mathrm{b} 1}=\frac{\rho_{\mathrm{S}}}{\varepsilon_{\mathrm{c}}}+\frac{\rho_{\mathrm{B}} \mathrm{a}_{1}}{\varepsilon_{\mathrm{c}}}$

The potential of the powder bed top portion is given as follows:

$$
\begin{aligned}
\left.\mathrm{V}\right|_{x=\mathrm{a} 1}=\int_{\mathrm{v}(\mathrm{b})}^{\mathrm{v}(\mathrm{a})} \mathrm{dV} & =\int_{-\mathrm{b}}^{\mathrm{a} 1}(-\mathrm{E}) \mathrm{dx}=\int_{-\mathrm{b}}^{0}\left(-\mathrm{E}_{\mathrm{b}}\right) \mathrm{dx} \\
& +\int_{0}^{\mathrm{a} 1}\left(-\mathrm{E}_{\mathrm{a}}\right) \mathrm{dx}
\end{aligned}
$$

Now, using Eqs. (2), (3), (15), and (18), the potential of the powder bed top portion can be found from

$$
\left.\mathrm{V}\right|_{x=\mathrm{a} 1}=\Delta \widetilde{\mathrm{V}}+\frac{\rho_{\mathrm{B}} \mathrm{a}_{1}^{2}}{2 \varepsilon_{\mathrm{a}}}=\mathrm{V}_{0}
$$

Since the upper vibrating electrode is subjected to the externally applied voltage $V_{0}$, we have

$$
\left.\mathrm{V}\right|_{x=\mathrm{a} 1}=\left.\mathrm{V}\right|_{x=\mathrm{a} 2}=\mathrm{V}_{0}
$$

Though the surface area of the electrode between the bottom of powder bed and the lower electrode is $\mathrm{S}$, it is assumed that the charged portion is concentrated primarily at the protruding area of the particles' surface. Therefore, let the area effectively taking part in the charging process be S'. Then, the surface charge density $\rho_{\mathrm{s}}$ is given by

$$
\rho_{\mathrm{s}}=\frac{\mathrm{q}_{\mathrm{s}}}{\mathrm{S}}=\varepsilon_{\mathrm{c}} \frac{\Delta \mathrm{VS}}{\mathrm{bS}}
$$

If the charge of the particle is zero, from Eqs. (13) and (22), we have

$$
\mathrm{V}_{0}=\frac{\rho_{\mathrm{S}} \mathrm{b}}{\varepsilon_{\mathrm{c}}}=\frac{\mathrm{S}^{\prime}}{\mathrm{S}} \Delta \mathrm{V}
$$

From the above equation, the externally applied voltage $V_{0}$ becomes equal to the contact potential difference $\Delta V$ only when $S^{\prime} / S$ is 1 .

Figure 4 shows the variation of the electric current and the displacement of the upper electrode with time, which are calculated by use of Eq. (12) with the experimental conditions specified in Table 1. Needless to say, the electric current $\mathrm{i}$ becomes zero when the upper vibrating electrode is at the top end or at the bottom end. The varying electric current was extremely small, about $10^{-12} \sim 10^{-14}$ (A) in the experimental conditions conducted for this report.

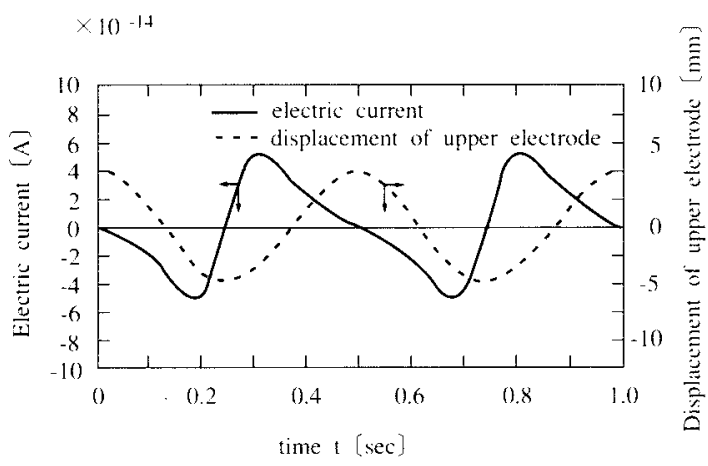

Fig. 4 Change of electric current and displacement of upper electrode with time

Table 1 Calculational conditions in Fig. 4

\begin{tabular}{lcr}
\hline Applied voltage & $\mathrm{V}_{\mathrm{o}}$ & $1(\mathrm{~V})$ \\
Frequency of vibrating electrode & $\omega$ & $12.56(\mathrm{rad} / \mathrm{s})$ \\
Thickness of powder bed & $\mathrm{a}_{\mathrm{a}}$ & $3(\mathrm{~mm})$ \\
Thickness of air phase $(\mathrm{B})$ & $\mathrm{b}$ & $4(\AA)$ \\
Pemittivity of air & $\varepsilon_{\mathrm{a}}$ & $8.84 \times 10^{-12}(\mathrm{~F} / \mathrm{m})$ \\
Permittivity of particle & $\varepsilon_{\mathrm{b}}$ & $8.84 \times 10^{-11}(\mathrm{~F} / \mathrm{m})$ \\
Charge density of particle layer & $\rho_{\mathrm{B}}$ & $0\left(\mathrm{C} / \mathrm{m}^{3}\right)$ \\
Surface charge density & $\rho_{\mathrm{S}}$ & $-0.15\left(\mathrm{C} / \mathrm{m}^{2}\right)$ \\
Area of electrode & $\mathrm{S}$ & $7.06 \times 10^{-4}\left(\mathrm{~m}^{2}\right)$ \\
Amplitude of vibrating electrode & $\alpha_{2}$ & $5(\mathrm{~mm})$ \\
\hline
\end{tabular}

\section{Results and Discussion}

Figure 5 shows one of the experimental results on the relation between the amplitude of the electric current and the externally applied voltage $V_{0}$. In this case, the electric current becomes zero when $V_{0}$ is about $-280 \mathrm{mV}$, which corresponds to the contact potential difference. The amplitude of the electric current was determined using an electrometer, which can automatically measure the electric current at 100 


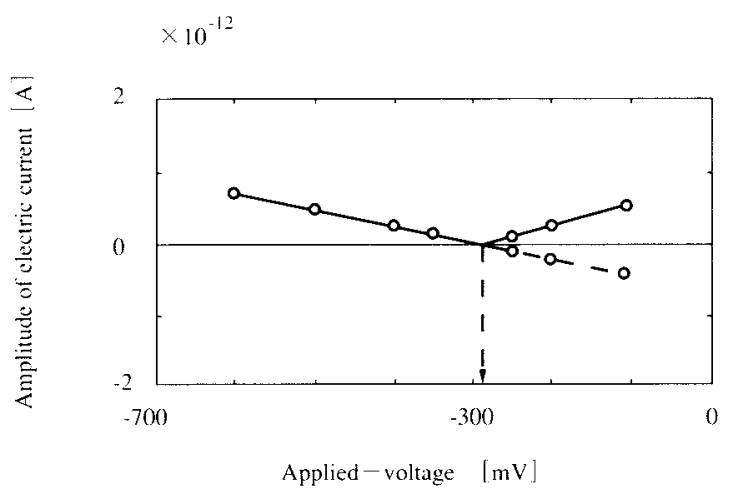

Fig. 5 Relation between amplitude of electric current and applied voltage

points per minute and indicate the maximum and minimum values.

The powder bed was adjusted in order to provide the specified packing ratio at the lower electrode and obtain the externally applied voltage which can nullify the electric current. The results indicated that the value $V_{0}$ varies in accordance with the measuring time. It is assumed that charges which the powder possessed at the initial stage of the measurement escaped through the grounding and the powder surface changed to the equilibrium surface condition adjusted to the environmental condition.

Figure 6 shows the relationship between the externally applied voltage which nullifies the electric current and the measuring time under various relative humidity conditions. The time within which $V_{0}$ exhibits a constant value increases as the relative humidity decreases.

Figure 7 shows the relationship between the externally applied voltage $V_{0}$ and the relative

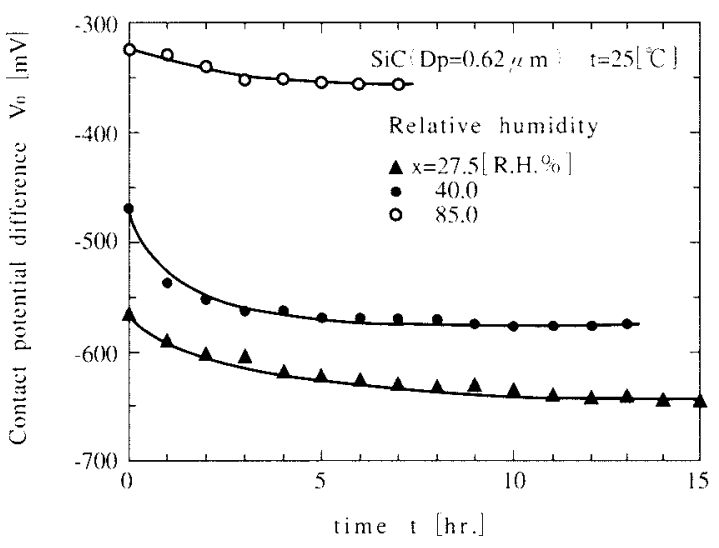

Fig. 6 Change of contact potential difference with time under different humidity conditions

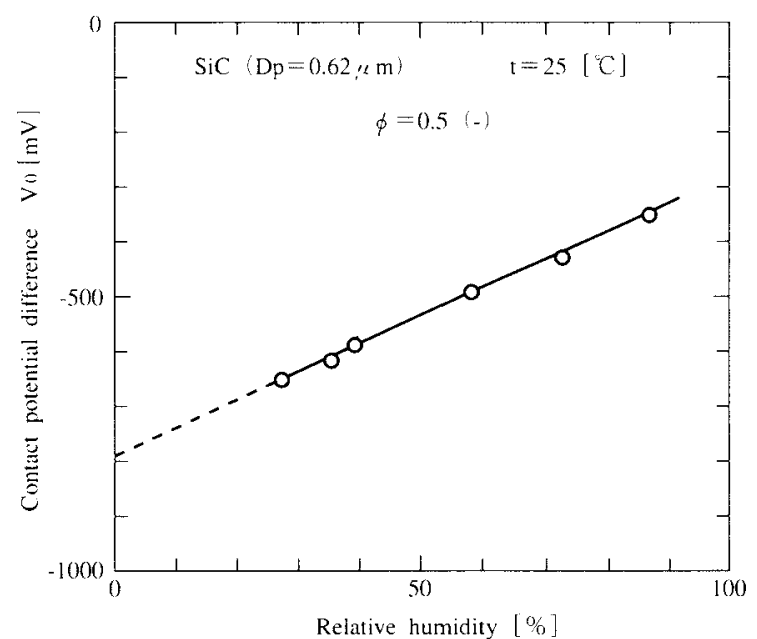

Fig. 7 Relation between contact potential difference and relative humidity

humidity when there is no change with time. As the relative humidity increases, the absolute value of $V_{0}$ approaches zero. It is assumed that as the relative humidity increases, water molecules physically adsorbed at the powder bed top and lower electrode surface increase, thus lowering the original contact potential difference generated between the powder bed and the metal.

\section{When the Powder Bed is Surface-modified with Alcohol:}

An investigation of the changes in the contact potential difference when fine particles are methanol-modified to vary the surface electrical properties was carried out.

The powder was surface-modified by a technique in which the desiccator bottom was filled with a methanol solution, and the powder was set in a Petri dish for a long time.

Figure 8 shows the experimental results. In the figure, open circles indicate the experimental results when the nonmodified powder is dried at $110^{\circ} \mathrm{C}$ for 24 hours, indicating that $V_{0}$ is constant at about $-500 \mathrm{mV}$. On the other hand, the powder modified with methanol for 24 hours (solid triangles) exhibits a constant $V_{0}$ value of $-400 \mathrm{mV}$ but shows a rapid change at the initial stage of the measurement. Based on these results, the powder of which the surface is modified with methanol has electrostatic characteristics which vary when methanol is adsorbed at the powder surface as compared to the conditions of nonmodified powder. In the 
experimental results in which the surface of the powder is modified over a period of 24 hours then dried again at $110^{\circ} \mathrm{C}$ for 12 hours (open triangles), the $\mathrm{V}_{0}$ value scarcely varies but the constant value at the end of the measuring time nearly agrees with that of the powder of which the surface is modified over a period of 24 hours.

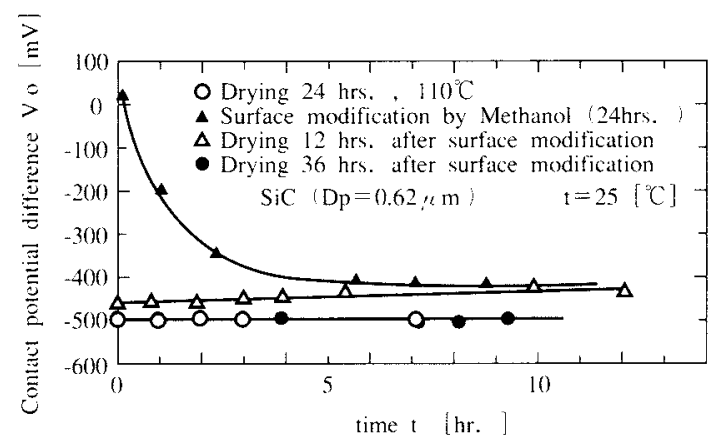

Fig. 8 Change of contact potential difference with time under different kinds of surface modification

However, the final value for the powder which is further dried at $110^{\circ} \mathrm{C}$ for 36 hours (solid circles) is nearly the same as that of the nonmodified powder. This may be attributed to the methanol molecules physically adsorbed by surface modification, which are desorbed by a long-period of drying. That. is, the surface modification method reported in this paper does not utilize reactions under high-temperature conditions, then methanol is easily desorbed from the powder surface because of weak bonding between the adsorbed methanol molecules and the powder.

As described above, the values measured by this technique enable the detection of subtle changes in the surface condition of the powder and may play an important role in the evaluation of the surface modification state of fine particles.

\section{Conclusion}

Experiments and a theoretical studies were carried out on the apparatus and the principle of measuring contact potential differences between powders and metals, and the following conclusions were obtained.

(1) New model was designed in order to interpret the experimental values of contact potential difference measurements. The study of the model has indicated that the contact potential difference between a powder and a metal can be measured only when the electric charge of the powder bed becomes zero.

(2) Because the electric charge of the powder bed decays and the powder surface shifts to a surface condition in equilibrium with the environmental conditions, a long time may be required to obtain a steady contact potential difference after the beginning of the measurement.

(3) The absolute value of the contact potential difference decreases as the relative humidity increases. This is attributed to a lowering of the contact potential difference originally existent between the powder and the metal due to the presence of water molecules between the two.

(4) The powder bed surface modified with methanol exhibits a contact potential difference different from that of the nonmodified powder. However, if adsorbed alcohol molecules are completely desorbed, the powder exhibits the same contact potential difference as that of the nonmodified powder.

\section{Nomenclature}

$a_{1} \quad:$ thickness of powder bed $\quad[\mathrm{m}]$

$\mathrm{a}_{2} \quad$ : position of upper vibrating electrode

- thickness of air phase between pow der bed and lower electrode $[\mathrm{m}]$

C : electrostatic capacity $[\mathrm{C} / \mathrm{V}]$

$\mathrm{D}_{\mathrm{p}} \quad$ : particle diameter $[\mathrm{m}]$

$\mathrm{E}_{\mathrm{a}}, \mathrm{E}_{\mathrm{b}}$ : electric field strength of powder and air phase, respectively $\quad[\mathrm{V} / \mathrm{m}]$

i : electric current [A]

$\mathrm{K}_{\mathrm{i}} \quad$ : constants in Eqs. (2)-(4) [V/m]

$\mathrm{S}, \mathrm{S}$ : area of electrode and effective contact area $\quad\left[\mathrm{m}^{2}\right]$

$\begin{array}{llr}t & : \text { time } & {[\mathrm{sec}]} \\ t_{1} & : \text { temperature } & {\left[{ }^{\circ} \mathrm{C}\right]}\end{array}$

$\mathrm{V}, \mathrm{V}_{0} \quad$ : electric potential and applied voltage

$[V]$

$\Delta V, \Delta \hat{V}:$ potential difference and contact potential difference $\quad[\mathrm{V}]$

$\mathrm{x} \quad$ : position [m]

$\alpha_{1}, \alpha_{2}$ : constants in Eq. (1) [m]

$\omega$ : frequency of upper vibrating electrode 
permittivities of particle and air, respectively

$[\mathrm{F} / \mathrm{m}]$

: volume charge density of powder layer

$\left[\mathrm{C} / \mathrm{m}^{3}\right]$

$\rho_{\mathrm{s}} \quad \begin{gathered}\text { : surface charge density of powder } \\ \text { layer }\end{gathered}$
$\rho_{\mathrm{se}} \quad \begin{gathered}{\left[\mathrm{C} / \mathrm{m}^{2}\right]} \\ \text { surface charge density of upper vi- }\end{gathered}$

$\begin{array}{cl}\rho_{\mathrm{s}} & \begin{array}{l}\text { surface charge density of powder } \\ \text { layer }\end{array} \\ \rho_{\mathrm{se}} & \begin{array}{l}{\left[\mathrm{C} / \mathrm{m}^{2}\right]} \\ \text { surface charge density of upper vi }\end{array}\end{array}$

$\begin{array}{cl}\rho_{\mathrm{s}} & \begin{array}{l}\text { surface charge density of powder } \\ \text { layer }\end{array} \\ \rho_{\mathrm{se}} & \begin{array}{l}{\left[\mathrm{C} / \mathrm{m}^{2}\right]} \\ \text { surface charge density of upper vi }\end{array}\end{array}$ brating electrode

$\left[\mathrm{C} / \mathrm{m}^{2}\right]$

$\phi \quad$ : packing fraction of particle $[-]$

$x \quad$ : relative humidity $\quad[\%]$

\section{References}

1 ) Kelvin, L.: Phil. Mag., 46, 82 (1898)

2) Krupp, H.: Advan. Collid Interface Sci., 1, 111 (1967)

3 ) Penney, G.W. and E.H. Klingler: Elec. AIEE, 200 (1962)

4 ) Yoshida, H., T. Ninomiya and H. Masuda: J. Soc. of Powder Technology, Japan, 26, 770 (1989) 